"You either sink or you swim, and you're better off swimming":

A qualitative study exploring the self-management experiences of soft tissue sarcoma survivors

Rahela Beghean, $\mathrm{MSc}^{1 *}$, Laura Coffey, $\mathrm{PhD}^{1}$

${ }^{1}$ Department of Psychology, Maynooth University, Maynooth, Co. Kildare, Ireland

*Present address: Dublin Mind Clinic, 165 Cabra Road, Dublin 7, Ireland

Corresponding author: Dr. Laura Coffey, Department of Psychology, Maynooth

University, Maynooth, Co. Kildare, Ireland (tel: +353 1 4747625, e-mail:

laura.coffey@mu.ie)

Declaration of competing interest: The authors declare that there is no conflict of interest.

Funding: This research did not receive any specific grant from funding agencies in the public, commercial, or not-for-profit sectors. 
5 Purpose: To qualitatively explore the consequences of soft tissue sarcoma and its treatment

6 experienced by survivors, the self-management strategies they use to deal with these

7 consequences, and any factors that may act as barriers or facilitators to their self-

8 management.

Conclusions: The findings of this study suggest that soft tissue sarcoma survivors, especially

\section{"You either sink or you swim, and you're better off swimming": A qualitative study exploring the self-management experiences of soft tissue sarcoma survivors}

\section{Abstract}

Methods: Semi-structured interviews were conducted with seven soft tissue sarcoma survivors who had completed their primary treatment. Interviews were audio-recorded, transcribed and thematically analysed.

Results: Physical, psychological and social consequences of soft tissue sarcoma and its treatment were identified, with side-effects, physical restrictions, body image issues, fear of recurrence, feeling depressed, familial relationships and sexual activity being the most frequently reported. Nine different types of self-management strategy encompassing eighteen specific strategies were identified, including cognitive strategies, lifestyle changes and utilisation of resources. Personal, social and environmental facilitators of self-management were identified; being in a relationship, being at an appropriate life stage, and having support from family, friends and medical staff were most commonly reported. Finally, personal and environmental barriers to self-management included the adaptation period, ongoing complications, rareness of sarcoma and poor patient-healthcare provider communication. those who are younger and experience physical limitations, may find the immediate post- 
24 treatment period particularly challenging and may benefit from nurse-led self-management 25 support.

26

27 Keywords: Sarcoma, self-management, cancer survivors, qualitative, rare cancer 


\section{Introduction}

2 Soft tissue sarcomas (STS) are a group of rare cancers that account for $1 \%$ of all

3 malignancies in adults (National Cancer Registry Ireland, 2014; Bhatt et al., 2016).

4 Originating from mesenchemal cells, STS can form in muscle, fat, cartilage, blood vessels or 5 any other tissues that support, surround or protect the body's organs. In Ireland, 176 cases of

6 STS are diagnosed annually on average, half of which occur in people aged under 60 years.

7 Treatment usually involves surgery, which may be combined with chemotherapy and, more

8 commonly, radiotherapy (NCRI, 2014). Depending on the tumour's location, significant side-

9 effects may be experienced including fatigue, nausea, weakness, hair loss, lymphoedema,

10 infertility and skin discoloration (Agarwal et al., 2017; Friedmann et al., 2011), in addition to

11 muscle weakness, mobility difficulties and persistent post-surgical pain (Agarwal et al.,

12 2017). STS survivorship is rising steadily due to ongoing improvements in diagnosis and

13 treatment (Gerrand and Furtado, 2017). In Ireland, individuals with STS have a five-year

14 relative survival rate of 56\% (NCRI, 2014; Bhatt et al., 2016).

15 As STS survivorship increases, so does the need to understand survivors' experiences,

16 challenges and needs (Almeida et al., 2021). The literature indicates that STS survivors may

17 experience a number of ongoing consequences including reduced mobility (Fauske et al.,

18 2015a, 2015b), elevated levels of anxiety and depression (Ostacoli et al., 2014) and

19 relationship disruptions (Martins et al., 2019). Gerrand and Furtado (2017) found that almost $50 \%$ of STS survivors live with long-term disability. Systematic reviews indicate that sarcoma survivorship has a detrimental impact on QoL, with lower levels than the general population being observed across the cancer trajectory (Winnette et al., 2016; McDonough et al., 2019). Sarcoma survivors are also reported to experience higher levels of anxiety and depression (van der Geest et al., 2012) and a higher incidence of suicide compared with the general population (Siracuse et al., 2017). Qualitative studies addressing the physical, 
psychological and social consequences of STS, and sarcoma more broadly, are sparse. Those conducted have focused predominantly on primary bone sarcoma (Fauske et al., 2015a, 2015b; Taylor and Pooley, 2018; Martins et al., 2019) either at specific points in the cancer trajectory or on specific aspects of survivors' experiences, such as impacts on employment (Parsons et al., 2008), daily activities, identity and body image (Fauske et al., 2015a, 2015b; Taylor and Pooley, 2017).

As can be seen from previous literature, STS survivors appear to encounter significant physical, psychological and social challenges during the post-treatment period and in the longer term. This underlines the importance of the survivor's role in the self-management of these consequences (Foster and Fenlon, 2011). Self-management may be defined as "an individual's ability to manage the symptoms, treatment, physical and psychosocial consequences and lifestyle changes inherent in living with a chronic condition" (Hoffman et al., 2013, p. 178). Although firmly established in the literature on long-term conditions such as diabetes (Lorig \& Holman, 2003), this concept has only recently gained traction (McCorkle et al., 2011) and become the focus of qualitative research (Dunne et al., 2017, 2018; Vinette \& Bilodeau, 2021) in the area of cancer survivorship. Self-management may be particularly important for STS survivors, given their relatively young age and the physical limitations they often experience as a result of treatment (Martins et al., 2019). More research is needed to understand in-depth the consequences of STS, how survivors attempt to selfmanage those consequences following primary treatment, and the various factors that may help or hinder them from successfully integrating self-management into their daily lives. Such information could help to inform healthcare providers (HCPs) and intervention developers on how best to support STS survivors in their self-management. treatment experienced by survivors; (b) the strategies STS survivors employed to self-manage 
these consequences; and (c) any factors that may have acted as barriers or facilitators to their self-management.

Method

5

Given the exploratory nature of the study, a qualitative design was employed. The

COnsolidated criteria for REporting Qualitative research (COREQ: Tong et al., 2017)

57 checklist was followed. Ethical approval was provided by Maynooth University's Department of Psychology Research Ethics Sub-Committee.

\section{Participants and recruitment procedure}

60 Individuals who i) were aged $\geq 18$ years, ii) had completed primary treatment for STS and iii)

61 were not awaiting or undergoing further treatment or palliative care were invited to participate. Recruitment was facilitated by the Irish Sarcoma Group (ISG), an association of specialist clinicians, nurses and supporting professionals who treat people with sarcoma on

64 the island of Ireland. Six potential participants were initially identified and approached by the

65 ISG to request permission to share their details with LC/RB, who then contacted them with

66 information about the study. All agreed to participate, but one withdrew from the study for

67 personal reasons. The remaining two participants contacted RB following the distribution of study flyers at an ISG patient information session. All individuals were emailed a study

69 information sheet and given the opportunity to ask questions before confirming their

70 participation. Demographic and clinical characteristics for the sample are provided in Table $71 \quad 1$. 
74 Semi-structured, face-to-face interviews were conducted with participants between October

\section{Results \\ Results}

and December 2019 by RB, a female novice researcher with no previous experience of conducting research on self-management or cancer survivorship. A topic guide based on interview questions from a qualitative study exploring self-management in head and neck cancer survivors (Dunne et al., 2018) was used. Questions broadly covered (a) challenges encountered during/after treatment, (b) self-management strategies used to deal with these challenges, and (c) perceived barriers and facilitators of self-managing these challenges. Interviews ranged in length from 30 to 136 minutes and were conducted in a setting of the participants' choosing: home $(n=4)$, a local café $(n=1)$ or hotel lobby $(n=1)$. Interviews were audio-recorded, transcribed verbatim, pseudonymised and de-identified by RB.

\section{Data analysis}

Interview transcripts were analysed inductively using MAXQDA software by the first author. Braun and Clarke's (2016) six-step model of thematic analysis was employed. Following an initial process of data immersion and familiarisation, pertinent and recurring aspects of the data were identified and appropriately coded. These codes were then analysed in isolation in order to purposefully identify themes and subthemes, which were related back to the coded data extracts and further refined to ensure coherence and eliminate redundancy. The last stage involved clearly defining and naming the themes and subthemes and re-reading the transcripts once more to confirm their suitability. The themes and subthemes identified by RB were reviewed and validated by LC, a researcher with experience in conducting research on self-management in cancer survivorship. A written report on the findings was also sent to participants for feedback. 
99 Seven individuals (five females, two males) aged between 25 and over 65 years were

100 interviewed (see Table 1; participants weren't asked for their specific age so as to preserve

101 their anonymity). Five participants were married or in a relationship, and four were retired.

102 Time since diagnosis ranged from 7 months to 10 years. Type of STS varied across the sample. Notable sequelae experienced by participants included lower limb amputation

104 (Susan) and mastectomy (Fiona).

106 Three overarching themes were identified in the analysis: consequences of STS and its

107 treatment, self-management strategies employed, and perceived facilitators and barriers to

108 self-management. Summaries of the themes and subthemes for each area, along with

109 illustrative quotations, can be found in the supplementary materials.

\section{Consequences of STS}

111 Participants experienced physical, psychological and social consequences as a result of STS

112 and its treatment.

\section{Physical consequences}

114 Three main physical consequences were reported by participants: side-effects $(n=7)$, physical

115 restrictions $(n=6)$ and body appearance $(n=6)$. Fatigue, either during or immediately after

116 treatment, was the most commonly reported treatment side-effect. Some experienced

117 unbearable post-operative pain, either due to the scar itself or having a rod placed. Susan,

118 who had an amputation as a result of STS, experienced phantom pain post-treatment.

119 Radiotherapy left long-lasting skin damage such as discoloration, rashes or scars, with which

120 almost every participant struggled. Other side-effects included poor sleep quality (mainly due 
121 to post-treatment pain), stiffness and tightness of joints, and a weakened immune system.

122 Many participants underwent surgery that involved the removal of muscle from their lower

123 limb, which considerably restricted their body movements. This was particularly evident for

124 Susan, a wheelchair user due to her amputation, who was very limited in terms of her

125 domestic and social activities, and noted how poorly adapted the physical environment was to

126 her needs. Changed body appearance as a result of treatment was another physical

127 consequence reported. Many participants experienced weight gain primarily due to reduced

128 mobility, especially at the start of the recovery period. In addition, some reported having a

129 "hefty scar" (Catherine) and "a strange looking leg” (Rebecca). Fiona, who had a

130 mastectomy as a result of angiosarcoma, experienced many difficulties adjusting to her new

131 appearance.

\section{Psychological consequences}

133 Participants experienced a great deal of psychological distress post-treatment, which was

134 subcategorised as follows: body image issues and low self-esteem $(n=5)$, fear of recurrence

135 (FoR: $n=5)$, feeling depressed $(n=4)$, feeling anxious $(n=4)$, loss of independence $(n=3)$, and

136 loss of control ( $n=3)$. Most participants reported that due to physical changes (e.g. weight

137 gain, amputation, mastectomy, scars, leg deformity) they felt differently about themselves

138 and their bodies, which impacted their self-esteem. For many, FoR was constantly present,

139 particularly coming up to a follow-up appointment or when noticing anything different on

140 their bodies. Niamh described how after her treatment, her FoR was so intense that it became

141 debilitating and impeded her from enjoying life.

142 Four participants talked about feeling depressed as a result of their STS and its treatment.

143 Some felt like they were losing their sense of self and turning into a different person as a

144 result of their sarcoma experience. A feeling of hopelessness was experienced by many, 
especially immediately post-treatment. Persistent mood changes were also reported. Certain treatment-induced consequences appeared to trigger depressive episodes. For example,

147 Rebecca found it hard to come to terms with having to get fertility treatment. Ongoing

148 complications seemed to worsen feelings of depression. Fiona, who had three surgical

149 procedures as part of her treatment, described how difficult it was for her to accept that she

150 had to go through another surgery. Four participants reported experiencing anxiety, which

151 persisted throughout their cancer journey. Rebecca became "more aware that anything could

152 happen to me or my family or my friends", which made her constantly anxious. Having

153 children, particularly of a younger age, appeared to add to participants' anxiety.

154 Some participants explained how their restricted mobility during the treatment and recovery period led to a loss of independence. Philip described how he was struck by his inability to engage in basic self-care; having nurses help him use the toilet made him feel like he had lost his "own dignity". This loss of independence was particularly evident for Susan following

158 her amputation, who felt she could "do nothing without help". Loss of control was experienced by some participants during treatment or when further surgical procedures were required. Having to rely on "those machines" and doctors for survival made Catherine feel helpless: “...you have no control, that's the worst part”.

\section{Social consequences}

163 STS and its treatment had a profound impact on social activity and wellbeing, resulting in disruptions to participants' familial relationships $(n=4)$, intimate relationships and sexual activity $(n=4)$, social roles $(n=3)$ and social interactions $(n=3)$. The impact on their

166 relationships with family members was frequently mentioned. Both Niamh and Fiona talked

167 about how their children were affected by their cancer. Niamh's children, who were young at 168 the time of her diagnosis, "took it very bad". Fiona too described how her daughters were "devastated", not only about her diagnosis but also at the realisation of their own personal 
vulnerability to STS, leading to feelings of fear and anxiety. Susan's physical limitations resulting from her amputation led her to feel isolated and detached from her family.

172 Most participants reported that their intimate relationships and sexual activity were affected

173 as a result of STS and its treatment. Rebecca described how her physical relationship with her partner changed as a result of her body esteem issues following treatment, which further diminished her confidence, self-esteem and overall psychological wellbeing. Fiona, who was separated, expressed concern about the possibility of getting into an intimate relationship

177 "down the road". Both Philip and Niall talked about how the physical consequences of their 178 surgery restricted their sexual functioning to some degree.

179 Some participants described how STS negatively impacted their social roles. Rebecca, who

180 was in her twenties when diagnosed, felt she was held back as when "all my friends were

181 having babies" she was "getting treatment or fertility treatments or injections or you

182 know...just getting my leg cut open”. Additionally, Niamh explained how her role as a

183 mother became more challenging once she got diagnosed with STS. She felt the constant 184 need to "play it down" to protect her children from the emotional distress but she was 185 "actually lying” to them, making the experience "very tough". Social interactions appeared 186 to be a bit more challenging for some participants following their STS and treatment. Susan

187 described how she first started going into shopping centres in a wheelchair and how 188 "everybody looks at someone in a wheelchair instantly." Rebecca also found it difficult to socialise as people didn't seem to understand that she still had side-effects despite having

190 finished treatment.

\section{Self-management strategies employed}

192 Participants engaged in a range of different self-management strategies to deal with the 193 challenges posed by STS and its treatment, including cognitive strategies ( $n=7)$, lifestyle 
194 changes $(n=6)$, utilisation of resources $(n=6)$, activity involvement $(n=5)$, self-esteem and

195 confidence management $(n=5)$, self-motivating $(n=5)$, self-monitoring $(n=5)$, goal setting

$196(n=3)$ and environmental changes $(n=2)$.

197 Cognitive strategies

198 Three cognitive strategies were identified as specific self-management techniques used by

199 participants: positive mindset $(n=6)$, acceptance $(n=6)$ and cognitive avoidance $(n=6)$.

200 Participants explained how having a positive mindset and being a "glass half-full" type of

201 person greatly helped them in overcoming the difficulties they encountered both during and

202 after treatment. They adopted this strategy through positive reappraisal of their situations and

203 reframing of their negative thoughts, repeatedly telling themselves that "there are worse

204 things" (Susan) and that "it's not going to kill me" (Philip). They also reminded themselves

205 of their abilities rather than their disabilities. The majority regarded themselves as lucky, for

206 either surviving, having a type of sarcoma which wasn't as "deadly as some of them"

207 (Niamh), or for "getting through it" (Fiona). Some simply refused to allow negative thoughts

208 to take over. Fiona highlighted the importance of such resilience in the face of the challenges

209 posed by STS and its treatment: "My attitude is you either sink or you swim and you're better

210 off swimming."

211 Almost every participant showed acceptance of STS and its consequences. Catherine referred

212 to the consequences of STS as "one of those things that you have to live with", while Niall

213 said that he "just sort of surrendered to it really". Fiona described how she could sometimes

214 become upset when looking in the mirror and "wishing things were a little bit better", but

215 she then reminded herself that there was nothing she could do: "This is you now... you get on

216 with it". Simply avoiding and blocking out negative thoughts and problems also appeared to

217 be quite an effective strategy for many participants. For example, Philip described how he 
218 dealt with the consequences of sarcoma by putting “it out of my mind completely...there's no

219 point in sitting here and biting your nails and thinking”.

220 Lifestyle changes

221 Two lifestyle change strategies were identified as specific self-management techniques used by participants: exercise $(n=6)$ and diet $(n=6)$. Exercise and generally being active appeared to be a very efficacious self-management strategy. Participants use various forms of exercise to manage the consequences of STS, including yoga, walking, swimming and cycling. Philip explained how he had started to exercise a lot more "just to keep things functional". Exercise helped Catherine to improve the bend in her knee: "I got to 30 degrees and... even since my femur now it's improved to 52". Niamh emphasised how exercise not only helped her to manage her pain and slowly reduce medications, but also to deal with the psychological consequences of sarcoma. Participants also reported that having a good diet helped them feel

230 healthier and at ease, whilst knowing that they were doing everything they could to prevent

231 recurrence of cancer.

\section{Utilisation of resources}

233 Four utilisation of resources strategies were identified as specific self-management

234 techniques: use of available information $(n=4)$, use of medication $(n=3)$, use of support services $(n=3)$ and use of technology $(n=2)$. Participants used various available resources such as the internet, books, and newspapers to keep themselves informed about their condition and how best to tackle the consequences of sarcoma. Fiona described how

238 attending an information session for sarcoma patients motivated her to ask for a further

239 follow-up. The use of medication helped some participants in managing sleep and pain.

240 Susan explained how after her amputation she experienced severe pain but took painkillers

241 whenever she felt the need. Likewise, Fiona experienced excruciating nerve pain after her 
242 mastectomy, which medications helped greatly; she described how she could not go to work

243 without taking “a couple of painkillers". Some participants availed of support services

244 regarding their psychological wellbeing. Rebecca mentioned that she had tried "various

245 things" such as attending a cancer support centre for counselling, as did Fiona. Some

246 participants explained how using technology helped them to self-manage. For example,

247 Catherine created a WhatsApp group with her friends and family which she used to keep

248 everyone informed by sending them photos of her radiotherapy treatment. She also used her

249 smartphone to journal and document her experiences during and after treatment. Fiona used

250 her smart TV to "go on YouTube and get on a Zumba class" whenever she didn't feel like

251 going for a walk or being outside, which helped her to maintain her exercise routine.

\section{Activity involvement}

253 Two activity involvement strategies were identified as specific self-management techniques:

254 having a preoccupation $(\mathrm{n}=4)$ and socialising $(\mathrm{n}=3)$. Participants explained how having

255 activities to preoccupy them allowed them to focus on something other than their problems.

256 Susan, Catherine and Fiona explained how their grandchildren kept them busy and brought

257 excitement and joy. To occupy her time, Fiona also did volunteering work and played bridge

258 with her friends and neighbours, which "keeps you going”. Rebecca explained how planning

259 for her wedding and "focusing on that and you know the dress... made life worth living

260 again". Socialising and interacting with others seemed to play an important role for some

261 participants in self-managing the consequences of sarcoma. Niamh stated that she did "have

262 the dark days" but "it's a lot to do with how solitary you are... you have to try meet people,

263 chat with people”.

264 Goal setting 
265 One goal setting strategy, planning and organising $(n=3)$, was identified as a specific selfmanagement technique. The physical consequences of sarcoma rendered many difficulties

267 and could be quite restricting for participants. However, some overcame those challenges by 268 planning and organising. Susan explained how she used to meet her siblings in hotel lobbies 269 as their homes weren't wheelchair accessible, but "that takes organising, nothing is 270 spontaneous".

\section{Self-esteem and confidence management}

272 One self-esteem and confidence management strategy, use of clothing and accessories $(n=4)$,

273 was identified as a specific self-management technique. Participants used clothing and accessories to conceal any changes to their bodies resulting from surgery and regain some of their self-esteem and confidence back. Niamh described how she felt self-conscious of the indentation in her thigh after the treatment, so she used "shoulder pads in the tights so it'll even it out". Similarly, Philip described how he got "built up heels" to conceal his limp. Fiona, who had a mastectomy as part of her treatment, used breast accessories that were "light wear but yet give you a shape”. Susan used appropriate clothing to help her regain some of her confidence back in being able to dress herself.

Self-motivating

Two main self-motivating strategies were identified as specific self-management techniques: living in the moment $(n=4)$ and seeking normality $(n=3)$. Some participants emphasised the importance of living in the moment and choosing life over psychological distress. For example, Fiona described how she retired a bit earlier simply to do things "while you're

286 healthy enough to do them... and that you can do them". Some participants dealt with the consequences of STS by seeking normality. Niamh explained how she went about trying to make herself feel normal again: "Yeah it's just family and friends trying to get you out of the 
house or going back to work trying to get your head into something. Em... trying... like even trying not to limp when I walked, just trying to get myself back to normal”.

291

\section{Self-monitoring}

292 Two self-monitoring strategies were identified as specific self-management techniques: monitoring side-effects $(n=3)$ and monitoring emotions $(n=3)$. Participants monitored the side-effects of their treatment, using "creams everyday" (Catherine) to minimise scarring or "fresh aloe vera" (Niall) for skin irritation. Fatigue was managed by taking breaks; for example, Catherine described how she would "go to the car and sit down" when she felt tired

297 from shopping. Participants had various ways of monitoring their emotions. Niamh hid her anxiety from her two children as she didn't want to put a burden on them. Philip explained that when he'd get anxious before a scan, he'd "say a prayer at night time and say 'I hope everything's going to be alright',".

Environmental changes

302 One environmental change strategy, housing adaptations $(n=2)$, was identified as a specific self-management technique. Two participants described how housing adaptations helped to accommodate their disability needs resulting from treatment. Susan, a wheelchair user, made many changes to her house including widening the front entrance, getting a stair lift and redesigning her entire bathroom. Similarly, Philip made adaptations to ensure that all the

307 facilities he needed were downstairs: "Shave, shower and all the rest".

\section{$308 \quad$ Perceived facilitators}

309 Ten facilitators of self-management were identified, which fell into three different categories:

310 personal, social and environmental facilitators. All three facilitator types were endorsed by

311 each participant $(n=7)$, with variation between the specific facilitators mentioned. 
313 Four personal facilitators were identified: being in a relationship $(n=5)$, appropriate life stage

$314(n=5)$, cancer literacy $(n=4)$, and private health insurance $(n=3)$. Most participants reported

315 that being in a relationship had greatly helped them in managing the consequences of STS.

316 Susan explained how her husband filled all the jobs of a carer, "cooking and minding and

317 bringing me everywhere", and that she would be "completely stuck" without him. Philip too

318 described how his wife was very supportive, especially when going through difficult times.

319 Catherine, who did not have a partner, explained that she managed perfectly well as "the

320 relationship that you have with your family and friends matters as much..."

321 Among older participants, there appeared to be a sense that their STS happened at a relatively

322 good time in their lives, as being older and having had life experience provided them with the

323 necessary coping skills to deal effectively with the consequences. For example, Niamh

324 explained how having a more limited social life as a result of her sarcoma did not affect her

325 as much because she was older now: “...maybe if I wasn't this age it'd be different but it suits

326 me not to be out every weekend you know. Whereas if I was younger, it'd probably have a

327 different impact you know." Some of the older participants also remarked that having

328 children who were already grown-up made their experiences easier to deal with.

329 Many participants reported that they had previous experience with, and knowledge of, cancer

330 and what it entailed. Susan lost her sister and father to cancer and was a cancer survivor

331 herself prior to her sarcoma. She felt like she "was nearly ready for what [the doctor] said"

332 when she received her STS diagnosis. Equally, Fiona had been diagnosed with cancer twice

333 before and also had family members who had cancer, so felt that she already knew a lot about

334 cancer. Having private health insurance also appeared to be quite beneficial for some

335 participants in regard to getting extra help in managing with the physical consequences of 

nurses from [private health service] would come every day..."

\section{Social facilitators}

339 Two social facilitators were identified: support from family and friends $(\mathrm{n}=7)$ and knowing

340 of, and relating to, other people with sarcoma $(n=3)$. Participants continuously emphasised

341 the importance and benefits of having supportive family members and friends. Each

342 participant had a good support system, which appeared to reduce the negative consequences

343 of sarcoma and facilitate self-management. For example, Susan described how supportive

344 and encouraging her family was - "their whole attitude was you know, this is not going to get

345 the better of you"- when she received the news of having to amputate her leg. Catherine also

346 explained how her radiotherapy treatment was a good experience for her as she had friends

347 who would accompany her to sessions. Some participants highlighted the benefits of knowing

348 of, and relating to, other people with sarcoma. Niamh described how she knew two people

349 with sarcoma while she had STS herself and how they had survived it. She found this helpful

350 as it gave her "a bit of hope especially when you're thinking it's a death sentence".

351 Furthermore, Philip and Catherine mentioned that they had met people at a sarcoma patient

352 information session and found people they could relate to.

\section{Environmental facilitators}

354 Two environmental facilitators were identified: medical staff $(n=7)$ and accessible places

$355(n=2)$. The care and treatment received from HCPs was highly praised by all participants.

356 There was a consensus that medical staff, particularly the nurses running the radiotherapy

357 sessions, were very caring and supportive: “...to be cared for by another human rather than

358 by an official or...some apparatchik within a system but by another human, it's a beautiful

359 thing" (Niall). Having disability-friendly and accessible places also greatly helped some 
360 participants in managing the physical consequences of STS. For example, Susan described

361 how she found going to concerts in a particular music venue very pleasant as their facilities

362 for wheelchair-users were "fabulous...they make it so easy".

\section{Perceived barriers}

364 Eight barriers to self-management were identified and subcategorised into personal and 365 environmental barriers.

\section{Personal barriers}

367 Four personal barriers were identified: adaptation period $(n=6)$, ongoing complications $(n=$

368 5), being younger $(n=4)$ and feeling like a burden and internalising $(n=2)$. Most participants 369 explained that once they had finished their treatment, there was an adaptation period where it 370 took them a while to "re-establish" themselves (Philip). This appeared to have been quite 371 challenging, and some took longer than others to regain some sense of normality. When asked about her self-management post-treatment, for example, Rebecca felt that she had managed poorly for the first two years following treatment: "I just didn't realise it was going to affect me the way it did afterwards. " Some participants experienced ongoing complications post-treatment which hindered self-management. For example, Susan acquired a hospital-based infection in addition to her amputation and as a result her leg wound never healed. This significantly impeded her recovery as she could not be fitted with a prosthesis. Philip too had an open wound on his ankle that would not heal due to its location.

379 As mentioned earlier, the life stage at which STS occurred appeared to have a significant 380 impact over the challenges it posed and how they were dealt with. Rebecca was the only participant who was under 45 when diagnosed, and a considerable difference could be seen between her and the others in regard to the challenges they faced. She described how she felt alienated from her peers as a result of her experiences and that her friends could not relate: 
"It's a bit lonely". Rebecca was also at the stage of wanting to become a mother, and appeared concerned about her ability to bear a child. At the start of her recovery, she hid herself away from family and friends "to not hurt them or not worry them". Niamh also internalised a lot of her psychological struggles and reported feeling like a burden.

\section{Environmental barriers}

Four environmental barriers were identified: rareness of sarcoma $(n=7)$, poor patient-HCP communication $(n=6)$, cost/health insurance $(n=2)$, and work $(n=2)$. A lack of sarcoma knowledge and awareness in both HCPs and the participants themselves was evident. Many expressed frustration with the length of time it took to get a sarcoma diagnosis. For example, it took Niamh more than three years to be diagnosed, which led to significant psychological distress. Furthermore, the rareness and heterogeneity of sarcoma delayed early intervention and treatment. Participants also commented on the dearth of information available on sarcoma, making it "the poor sister of cancers, like Cinderella in the fairytale, being the little one who got nothing" (Susan).

Almost all participants reported a lack of information and guidance provided by HCPs posttreatment, which substantially impeded their ability to self-manage. Two participants explained their frustration with the failure of HCPs to provide information on the potential complications and side-effects that could arise in the short- or long-term. Susan explained how she received no prior notice that her mobility would be so compromised following surgery: "I had no warning that this is how it would be". Similarly, Rebecca described how

404 she received no aftercare once she was out of the hospital and believed that if she had, "I 405 wouldn't have been so sad as I was for as long as I was... ” Both Catherine and Susan 406 explained how they received no guidance on performing activities of daily living such as showering or bathing: “...you have to find all these things out for yourself” (Susan). Susan 
also emphasised that there was no link between the hospital and the community and how she was misled into thinking that "there's going to be people arriving at the door when you got home to say we're here and we 're going to help you now'. The punitive cost of private healthcare also posed a barrier to self-management. For example, some participants could not afford to pay for private physiotherapy sessions, which impeded their recovery. Although most participants were retired, those in full-time employment felt that work got in the way of their recovery. For example, Rebecca felt that she may have returned to work too soon and should have focused more on her wellbeing rather than "rushing trying to get back to the normality”.

\section{Discussion}

To the authors' knowledge, this is the first study to explore the self-management experiences of STS survivors. The findings indicate that, similar to other cancers, STS poses many significant and enduring physical, social and psychological challenges to those who have completed their primary treatment (Institute of Medicine, 2006). The side-effects experienced by participants (e.g. fatigue, pain, skin damage, insomnia etc.) align with previous literature on STS (McDonough et al., 2019; Reichardt et al., 2012; van der Geest et al., 2012). Along with changed body appearance and restricted mobility due to muscle weakness, poor motor control, and lower limb amputation in one instance, they interfered with participants' daily activities, relationships and social participation, intensifying feelings of depression, anxiety and body image issues, FoR and loss of independence. This supports previous research identifying common concerns and unmet needs in sarcoma survivors (Gerrand and Furtado,

430 2017; McDonough et al., 2019; Storey et al., 2019) and suggests that some may require 431 formal psychological support, particularly in the immediate post-treatment period. FoR, a common and often debilitating outcome of cancer and its treatment (Koch et al., 2013), was 
reported by the majority of participants in the present study. This suggests that FoR is a

434 potentially significant yet overlooked issue for sarcoma survivors (Martins et al., 2020) that

435 requires further investigation and merits consideration by clinicians in planning surveillance

436 post-treatment (Hovgaard et al., 2017). Furthermore, a number of issues specific to

437 participants with mobility limitations were raised; such individuals may benefit from

438 additional practical supports following treatment such as occupational therapy and housing

439 adaptation grants (McKenzie and Barker, 2021).

440 Despite these challenges, participants successfully employed an array of self-management

441 strategies that helped them to deal with the consequences of STS and its treatment. The

442 strategies they described mirror those used by survivors of other cancers (Dunne et al., 2017;

443 Yun et al., 2015) as well as individuals living with other long-term conditions (Schulman-

444 Green et al., 2012). A self-management strategy commonly employed by participants was

445 having a positive mindset. Reframing negative thoughts and positively appraising their

446 experiences appeared to increase their sense of control over their situation, allowing them to

447 develop an inner belief that they could overcome their cancer and construe a positive future

448 for themselves, as noted in other qualitative studies of sarcoma survivors (Taylor and Pooley,

449 2018; Martins et al., 2019). Adopting a healthy lifestyle through diet and exercise was also

450 frequently reported, consistent with many reviews and theoretical models of self-management

451 in cancer (Boland et al., 2018; Ferioli et al., 2018). The frequent use of cognitive avoidance

452 as form of self-management echoes research suggesting that avoidance and denial can be at

453 times efficacious in dealing with adaptation challenges (Dunne et al., 2014; Kortte et al.,

454 2009). Given relatively low survival and high recurrence rates in this cohort (NCRI, 2014),

455 avoiding negative thoughts may have a protective effect, as observed with other cancers

456 (Humphris et al., 2003). 
With regard to participants' perceived facilitators of self-management, being in a relationship and having support from family and friends played a critical role in supporting them through their cancer journey, particularly during the post-treatment period. Similar findings have been noted regarding sarcoma (Gerrand and Furtado, 2017; Martins et al., 2019), as well as in the broader cancer literature (Decker, 2006). While the expertise of medical staff was highly valued, it was the support they provided that really shaped participants' experiences. This was particularly evident in their descriptions of the care they received from nurses, who provided them with emotional as well as practical support and were readily available even during the post-treatment phase. Similar findings have been observed in other research on sarcoma survivorship (Martins et al., 2019; Rajasekaran et al., 2021), indicating the potential value of specialised nursing roles such as the Sarcoma Clinical Nurse Consultant positions currently being piloted in Australia (Weaver et al., 2021).

Although some consequences of STS equally impacted all age groups, participants' age appeared to shape their experiences in different ways. For example, although those who were retired felt that "it happened at a right time" as they had their social roles such as careers, relationships, parenthood, etc. "fulfilled" for the most part, the youngest participant, who was wanting to start a family at the time of the study, felt that her age and life stage posed a barrier to effective self-management. This mirrors previous research (Martins et al., 2019; McDonough et al., 2019; Fauske et al., 2015b) and suggests that life stage can be a doubleedged sword for STS survivors, with post-treatment challenges, particularly physical limitations, causing more disruptions to social roles for young adults. Conversely, Fauske and colleagues (2015a) found that some younger adults with primary bone sarcoma viewed their experiences positively and as an opportunity to reorient their lives. More research is required

480 to investigate these differences and further our understanding of how age impacts people's 481 responses to the consequences of STS. Additionally, although only two male participants 
were included in the sample, they appeared to experience physical barriers to sexual functioning to a greater extent than our female participants.

484 Lastly, poor patient-HCP communication rendered many difficulties for participants in terms 485 of their self-management. Although most reported positive experiences with medical staff 486 during treatment, they lacked adequate aftercare and felt ill-prepared for the post-treatment 487 phase, having received no practical guidance, emotional support or information on late or long-term effects. This echoes the literature on cancer survivors getting "lost in transition"

489 (Institute of Medicine, 2006), with ineffective HCP-patient communication being one of the 490 most frequently cited reasons for poor care experiences (Franco et al., 2016; Hudson et al., 491 2012; Leonard, 2017; Martins et al., 2019; Weaver et al., 2020).

\section{Strengths and limitations}

493 This study provides a rich, detailed description of how STS survivors negotiate the challenges they face following treatment and the various facilitators and barriers they encounter in this process. There were a number of limitations to the study, however, that should be taken into account. Firstly, the sample was small and predominantly female, and all participants were

497 from a middle-upper class White Irish background. Furthermore, all participants underwent 498 radiation therapy, which is associated with specific side-effects and consequences that may 499 not be relevant to those who do not receive this type of treatment. Nevertheless, the sample 500 captures a diversity of ages and sequelae of STS and its treatment including amputation, 501 mastectomy and impaired wound healing, and is of a similar size to other recent qualitative 502 studies of STS (Dewhurst et al., 2020) and self-management (Vinette \& Bilodeau, 2021).

503 Moreover, as the main aim of qualitative research is to illuminate the phenomena of

504 participants' experiences, we believe that these limitations were balanced out by the richness and depth of the information obtained, and the identification of common challenges and 
experiences despite the heterogeneity of the sample. Although the study's cross-sectional

507 design did not allow for exploration of changes in participants' experiences over time, the

508 amount of time that had passed since completing treatment varied from seven months to over

509 ten years across participants, thus capturing a range of points along the cancer survivorship

510 trajectory. Future longitudinal research could help to establish whether, and how, the

511 consequences of STS and their management fluctuate within individuals over time. Finally,

512 although only one author conducted the thematic analysis, the themes and subthemes were

513 verified by another author with relevant expertise and the participants themselves, reinforcing

514 the validity and credibility of the findings.

\section{Implications for nursing practice}

516 Although STS survivors appear to engage in a range of self-management strategies, they

517 experience many impediments to doing so effectively, including a lack of information about

518 the long-term and late effects of STS and its treatment. Nurses, who evidently play an

519 important role in the practical and emotional support of sarcoma survivors during their treatment, may be best placed to provide self-management support through the provision of

521 education on what to expect post-treatment, how to manage common challenges, and

522 signposting of available resources. This could be formalised through the provision of training

523 to enhance nurses' competencies in self-management support as well as the development of

524 nurse-led self-management interventions, both of which have been found to improve patient outcomes (Coster and Norman, 2009; Duprez et al., 2017; Massimi et al., 2017).

526 Consideration should be given to contextual factors that influence nurses' ability to provide

527 self-management support when developing and implementing such interventions (Tharani et 528 al., 2021). 


\section{Conclusion}

531 STS survivorship entails a range of post-treatment challenges for which survivors develop

532 self-management strategies that can be enabled or impeded by various factors. Through these

533 challenges, STS survivors have to either "sink or swim, and [are] better off swimming" to

534 overcome barriers in order to achieve their goals. The findings indicate that there is a need to

535 develop training programmes and targeted interventions which enable nurses to support STS

536 survivors in their self-management, particularly those who are younger and/or experience

537 significant physical impairment, and empower them to live well after primary treatment.

538

539

540 Acknowledgements: We wish to thank Dr. Charles Gillham and the Irish Sarcoma Group for

541 facilitating recruitment, and our participants for giving so generously of their time and

542 experiences. 


\section{References}

Agarwal, S., Cicone, C., Pipia, P.A., Maheshwari, A.V., 2017. Rehabilitation for patients with bone and soft tissue sarcoma, in: Henshaw, R.M. (Ed.), Sarcoma: A Multidisciplinary Approach to Treatment. Springer, New York, pp. 295-311.

Almeida, A., Martins, T., Lima, L., 2021. Patient-reported outcomes in sarcoma: A scoping review.

Eur J Oncol Nurs. 50, 101897. https://doi.org/10.1016/j.ejon.2021.101897

Anderson, C., 2010. Presenting and evaluating qualitative research. Am J Pharm Educ. 74(8), 141. https://doi.org/10.5688/aj7408141 Bhatt, N., Deady, S., Gillis, A., Bertuzzi, A., Fabre, A., Heffernan, E., et al., 2015. Epidemiological study of soft-tissue sarcomas in Ireland. Cancer Med. 5(1), 129-135. https://doi.org/10.1002/cam4.547

Bhuva, N., Li, S.P., Maher, J., 2012. Living with and beyond cancer: New challenges, in: Mohan, R. (Ed.), Topics in Cancer Survivorship. InTech, Rijeka, pp 1-12.

Boland, L., Bennett, K., Cuffe, S., Gleeson, N., Grant, C., Kennedy, J., Connolly, D., 2018. Cancer survivors' experience of OptiMal, a 6-week, occupation-based, self-management intervention. Brit J Occup Ther. 82(2), 90-100. https://doi.org/10.1177\%2F0308022618804704

Braun, V., Clarke, V., 2006. Using thematic analysis in psychology. Qual Res Psychol. 3(2), 77-101. doi: 10.1191/1478088706qp063oa

Coster, S. and Norman, I., 2009. Cochrane reviews of educational and self-management interventions to guide nursing practice: A review. Int J Nurs Stud. 46(4), 508-528. https://doi.org/10.1016/j.ijnurstu.2008.09.009

Decker, C., 2006. Social support and adolescent cancer survivors: A review of the literature. Psychooncology. 16(1), 1-11. https://doi.org/10.1002/pon.1073 
Dewhurst, S, Tigue, R., Sandsund, C., Mein, G., Shaw, C., 2020. Factors influencing people's ability to maintain their activity levels during treatment for soft tissue sarcoma - A qualitative study. Physiother Theory Pract. 36(8), 923-932. https://doi.org/10.1080/09593985.2018.1519622

Dunne, S., Coffey, L., Gallagher, P., Desmond, D., 2014. “If I can do it I will do it, if I can’t, I can't": A study of adaptive self-regulatory strategies following lower limb amputation. Disabil Rehabil. 36(23), 1990-1997. https://doi.org/10.3109/09638288.2014.885993

Dunne, S., Mooney, O., Coffey, L., Sharp, L., Timmons, A., Desmond, D., et al., 2017. Selfmanagement strategies used by head and neck cancer survivors following completion of primary treatment: A directed content analysis. Psychooncology. 26(12), 2194-2200. https://doi.org/10.1002/pon.4447

Dunne, S., Coffey, L., Sharp, L., Timmons, A., Desmond, D., Gooberman-Hill, R., et al., 2018. Barriers to active self-management following treatment for head and neck cancer: Survivors' perspectives. Psychooncology. 27(10), 2382-2388. https://doi.org/10.1002/pon.4835

Duprez, V., Vandecasteele, T., Verhaeghe, S., Beeckman, D. and Van Hecke, A., 2017. The effectiveness of interventions to enhance self-management support competencies in the nursing profession: a systematic review. J Adv Nurs. 73(8), 1807-1824. https://doi.org/10.1111/jan.13249

Fauske, L., Bondevik, H., Bruland, Ø.S., Ozakinci, G., 2015. Negative and positive consequences of cancer treatment experienced by long-term osteosarcoma survivors: a qualitative study. Anticancer Res. 35(11), 6081-6090.

Fauske, L., Bruland, O., Grov, E., Bondevik, H., 2015. Cured of primary bone cancer, but at what cost: A qualitative study of functional impairment and lost opportunities. Sarcoma. 2015, 484196. https://doi.org/10.1155/2015/484196 
Fauske, L., Lorem, G., Grov, E., Bondevik, H., 2015. Changes in the body image of bone sarcoma survivors following surgical treatment - A qualitative study. J Surg Oncol. 113(2), 229-234. https://doi.org/10.1002/jso.24138

Ferioli, M., Zauli, G., Martelli, A., Vitale, M., McCubrey, J., Ultimo, S., et al., 2018. Impact of physical exercise in cancer survivors during and after antineoplastic treatments. Oncotarget. 9(17), 14005-14034. https://doi.org/10.18632/oncotarget.24456

Foster, C., Fenlon, D., 2011. Recovery and self-management support following primary cancer treatment. Brit J Cancer. 105, S21-S28. https://doi.org/10.1038/bjc.2011.419

Franco, B., Dharmakulaseelan, L., McAndrew, A., Bae, S., Cheung, M., Singh, S., 2016. The experiences of cancer survivors while transitioning from tertiary to primary care. Curr Oncol. 23(6), 378-385. https://doi.org/10.3747/co.23.3140

Friedmann, D., Wunder, J. S., Ferguson, P., O’Sullivan, B., Roberge, D., Catton, C., et al., 2011. Incidence and severity of lymphoedema following limb salvage of extremity soft tissue sarcoma. Sarcoma. 2011, 289673. https://doi.org/10.1155/2011/289673

Gerrand, C., Furtado, S., 2017. Issues of survivorship and rehabilitation in soft tissue sarcoma. Clin Oncol (R Coll Radiol). 29(8), 538-545. https://doi.org/10.1016/j.clon.2017.04.001

Hoffman, M., Lent, R., Raque-Bogdan, T., 2013. A social cognitive perspective on coping with cancer. Couns Psychol. 41(2), 240-267. https://doi.org/10.1177\%2F0011000012461378

Horick, N. K., Manful, A., Lowery, J., Domchek, S., Moorman, P., Griffin, C., et al., 2016. Physical and psychological health in rare cancer survivors. J Cancer Surviv. 11(1), 158-165. https://doi.org/10.1007/s11764-016-0573-0 
Hovgaard, T.B., Nymark, T., Skov, O. and Petersen, M.M., 2017. Follow-up after initial surgical treatment of soft tissue sarcomas in the extremities and trunk wall. Acta Oncol. 56(7), 10041012. https://doi.org/10.1080/0284186X.2017.1299937

Hudson, S., Miller, S., Hemler, J., Ferrante, J., Lyle, J., Oeffinger, K., DiPaola, R., 2012. Adult cancer survivors discuss follow-up in primary care: 'Not what I want, but maybe what I need'. Ann Fam Med. 10(5), 418-427. https://doi.org/10.1370/afm.1379

Humphris, G., Rogers, S., McNally, D., Lee-Jones, C., Brown, J., Vaughan, D., 2003. Fear of recurrence and possible cases of anxiety and depression in orofacial cancer patients. Int $\mathbf{J}$ Oral Maxillofac Surg. 32(5), 486-491. https://doi.org/10.1016/S0901-5027(03)90399-1

Institute of Medicine, 2006. From Cancer Patient To Cancer Survivor: Lost In Transition. The National Academies Press, Washington, DC. https://doi.org/10.17226/11468.

Koch, L., Jansen, L., Brenner, H. and Arndt, V., 2013. Fear of recurrence and disease progression in long-term ( $\geq 5$ years) cancer survivors - a systematic review of quantitative studies. Psychooncology. 22(1), 1-11. https://doi.org/10.1002/pon.3022

Kortte, K., Veiel, L., Batten, S., Wegener, S., 2009. Measuring avoidance in medical rehabilitation. Rehabil Psychol. 54(1), 91-98. https://doi.apa.org/doi/10.1037/a0014703

Kwong, T.N.K., Furtado, S., Gerrand, C., 2014. What do we know about survivorship after treatment for extremity sarcoma? A systematic review. Eur J Surg Oncol. 40(9), 1109-1124. https://doi.org/10.1016/j.ejso.2014.03.015

Leonard, P., 2017. Exploring ways to manage healthcare professional-patient communication issues. Support Care Cancer, 25(Suppl 1), 7-9. https://doi.org/10.1007/s00520-017-3635-6

Lorig, K., Holman, H., 2003. Self-management education: History, definition, outcomes, and mechanisms. Ann Behav Med. 26(1), 1-7. https://doi.org/10.1207/S15324796ABM2601_01 
Maher, E.J., 2012. Managing the consequences of cancer treatment and the English National Cancer Survivorship Initiative. Acta Oncol. 52(2), 225-232. https://doi.org/10.3109/0284186X.2012.746467

Martins, A., Whelan, J., Bennister, L., Fern, L., Gerrand, C., Onasanya, M., et al., 2019. Qualitative study exploring patients experiences of being diagnosed and living with primary bone cancer in the UK. BMJ Open. 9(9), e028693. doi: 10.1136/bmjopen-2018-028693

Martins, A., Bennister, L., Fern, L.A., Gerrand, C., Onasanya, M., Storey, L., et al., 2020.

Development of a patient-reported experience questionnaire for patients with sarcoma: the Sarcoma Assessment Measure (SAM). Qual Life Res. 29, 2287-2297. https://doi.org/10.1007/s11136-020-02481-x

Massimi, A., De Vito, C., Brufola, I., Corsaro, A., Marzuillo, C., Migliara, G., et al., 2017. Are community-based nurse-led self-management support interventions effective in chronic patients? Results of a systematic review and meta-analysis. PLoS ONE. 12(3), e0173617. https://doi.org/10.1371/journal.pone.0173617

McCorkle, R., Ercolano, E., Lazenby, M., Schulman-Green, D., Schilling, L. S., Lorig, K., \& Wagner, E. H. (2011). Self-management: Enabling and empowering patients living with cancer as a chronic illness. CA: A Cancer Journal for Clinicians, 61(1), 50-62. https://doi.org/10.3322/caac.20093

McDonough, J., Eliott, J., Neuhaus, S., Reid, J., Butow, P., 2019. Health-related quality of life, psychosocial functioning, and unmet health needs in patients with sarcoma: A systematic review. Psychooncology. 28(4), 653-664. https://doi.org/10.1002/pon.5007

McKenzie, C., and Barker, K., 2021. Occupational therapy rehabilitation for sarcoma patients following limb salvage surgery: a scoping review. Disabil Rehabil. 43(2), 284-296. https://doi.org/10.1080/09638288.2019.1620874 
National Cancer Registry Ireland, 2014. Cancer Trends - Soft Tissue Sarcomas.

https://www.ncri.ie/sites/ncri/files/pubs/Soft-Tissue-Sarcomas-v2.pdf (accessed 30 June 2021)

National Cancer Registry Ireland, 2016. Cancer in Ireland 1994-2014: Annual Report of the National Cancer Registry. https://www.ncri.ie/sites/ncri/files/pubs/NCRReport_2016.pdf (accessed 30 June 2021)

Ostacoli, L., Saini, A., Zuffranieri, M., Boglione, A., Carletto, S., De Marco, I., Lombardi, I., Picci, R.L., Berruti, A. and Comandone, A., 2014. Quality of life, anxiety and depression in soft tissue sarcomas as compared to more common tumours: an observational study. Appl Res Qual Life. 9(1), 123-131.

Parsons, J., Eakin, J., Bell, R., Franche, R., Davis, A., 2008. “So, are you back to work yet?” Reconceptualizing 'work' and 'return to work' in the context of primary bone cancer. Soc Sci Med. 67(11), 1826-1836. https://doi.org/10.1016/j.socscimed.2008.09.011

Podleska, L., Kaya, N., Farzaliyev, F., Pöttgen, C., Bauer, S., Taeger, G., 2017. Lower limb function and quality of life after ILP for soft-tissue sarcoma. World J Surg Oncol. 15, 84.https://doi.org/10.1186/s12957-017-1150-3

Rajasekaran, R.B., Khatkar, H. and Kotecha, S., 2021. The role of specialist nurses in delivering effective care in a tertiary sarcoma referral service. J Clin Orthop Trauma. 20, 101501. https://doi.org/10.1016/j.jcot.2021.101501

Reichardt, P., Leahy, M., Muro, X.G.D., Ferrari, S., Martin, J., Gelderblom, H., et al., 2012. Quality of life and utility in patients with metastatic soft tissue and bone sarcoma: The Sarcoma Treatment and Burden of Illness in North America and Europe (SABINE) Study. Sarcoma. 2012, 740279. https://doi.org/10.1155/2012/740279 
Siracuse, B., Gorgy, G., Ruskin, J., Beebe, K., 2017. What is the incidence of suicide in patients with bone and soft tissue cancer? : Suicide and sarcoma. Clin Orthop Relate Res. 475(5), 14391445. doi: 10.1007/s11999-016-5171-y

Storey, L., Fern, L., Martins, A., Wells, M., Bennister, L., \& Gerrand, C. et al. (2019). A critical review of the impact of sarcoma on psychosocial wellbeing. Sarcoma, 2019, 1-18. doi: $10.1155 / 2019 / 9730867$

Taylor, M., Pooley, J., 2017. Sarcoma survivors' perspectives on their body image and functional quality of life post-resection/limb salvage surgery. Eur J Cancer Care. 26(6), e12667. https://doi.org/10.1111/ecc. 12667

Taylor, M., Pooley, J., 2018. Life is precious: Sarcoma/giant-cell tumors survivors' perspectives on their psychological journey. J Psychosoc Oncol. 36(6), 681-699. https://doi.org/10.1080/07347332.2018.1498425

Tharani, A., Van Hecke, A., Ali, T.S. and Duprez, V., 2021. Factors influencing nurses' provision of self-management support for patients with chronic illnesses: A systematic mixed studies review. Int J Nurs Stud. 120, 103983. https://doi.org/10.1016/j.ijnurstu.2021.103983

Tong, A., Sainsbury, P. and Craig, J., 2007. Consolidated criteria for reporting qualitative research (COREQ): a 32-item checklist for interviews and focus groups. Int J Qual Health Care. 19(6), 349-357. https://doi.org/10.1093/intqhc/mzm042

van der Geest, I., Knoop, H., Veth, R., Schreuder, H., Bleijenberg, G., 2012. High fatigue scores before and after surgical treatment of bone and soft tissue tumors. Exp Ther Med. 5(1), 205208. https://doi.org/10.3892/etm.2012.786 
Vinette, B. and Bilodeau, K., 2021. Progression of self-management learning experiences of young adults following an allogeneic hematopoietic stem cell transplantation: A qualitative study. Eur J Oncol Nurs. 52, 101951. https://doi.org/10.1016/j.ejon.2021.101951

Weaver, R., O'Connor, M., Sobhi, S., Carey Smith, R. and Halkett, G., 2020. The unmet needs of patients with sarcoma. Psychooncology. 29(7), 1209-1216.

Weaver, R., O'Connor, M., Ngune, I., Smith, R.C., Phillips, J. and Halkett, G., 2021. Perspectives of the Sarcoma Clinical Nurse Consultant role: A qualitative study. Collegian. Online first publication. https://doi.org/10.1016/j.colegn.2020.12.006

Winnette, R., Hess, L., Nicol, S., Tai, D., Copley-Merriman, C., 2016. The patient experience with soft tissue sarcoma: A systematic review of the literature. Patient. 10(2), 153-162. https://doi.org/10.1007/s40271-016-0200-1

Yun, Y., Jung, J., Sim, J., Choi, H., Lee, J., Noh, D., et al., 2015. Patient-reported assessment of selfmanagement strategies of health in cancer patients: development and validation of the Smart Management Strategy for Health Assessment Tool (SAT). Psychooncology. 24(12), 1723 1730. https://doi.org/10.1002/pon.3839 
Table 1. Demographic and clinical characteristics of the sample

\begin{tabular}{lllllll}
\hline Participant & Age & $\begin{array}{l}\text { Marital } \\
\text { status }\end{array}$ & $\begin{array}{l}\text { Employment } \\
\text { status }\end{array}$ & $\begin{array}{l}\text { Time since } \\
\text { diagnosis }\end{array}$ & $\begin{array}{l}\text { Type of soft tissue } \\
\text { sarcoma }\end{array}$ & Other \\
\hline Susan & $55+$ & Married & Retired & 2.5 years & Myxofibrosarcoma & Amputation \\
Rebecca & $25+$ & Married & Working & $\begin{array}{l}4.5 \text { years } \\
\text { Other STS }\end{array}$ & - \\
Niamh & $45+$ & Single & Working & 10.5 years & Myxoid & - \\
& & & & liposarcoma & \\
Philip & $65+$ & Married & Retired & 7 years & Synovial sarcoma & - \\
Catherine & $55+$ & Married & Retired & 10 months & Other STS & - \\
Niall & $55+$ & In a & Working & 7 months & Other STS & - \\
& & relationship & & & & Angiosarcoma \\
Fiona & $65+$ & Separated & Retired & 3 years & Mastectomy \\
\hline
\end{tabular}

